\title{
Reproduction of the Intertidal Sponge Hymeniacidon perlevis (Montagu) Along a Bathymetric Gradient
}

\author{
Elda Gaino ${ }^{*}, 1$, Cardone Frine ${ }^{2}$ and Corriero Giuseppe ${ }^{2}$ \\ ${ }^{I}$ Dipartimento di Biologia Cellulare e Ambientale - Università degli Studi di Perugia, Italy \\ ${ }^{2}$ Dipartimento di Biologia Animale ed Ambientale - Università degli Studi di Bari, Italy
}

\begin{abstract}
The reproductive cycle of the demosponge Hymeniacidon perlevis (Montagu) was investigated at the Mar Piccolo di Taranto (Ionian Sea, Apulian). According to the distribution of the specimens, along a bathymetric gradient, sponges have been subdivided in two groups, named group A and group B. The former was made up of specimens that are usually exposed in the air when there is a low water level and the latter by specimens that are constantly submerged. Monthly monitoring (February 2006 - January 2007) of twenty tagged specimens (ten in each group) was carried out in order to compare the reproductive efforts in the two groups. The reproductive pattern differed slightly between the two groups; the majority of the females in group B restrict oocyte production till May. In addition, group A exhibits a significantly higher density of sexual elements, than those belonging to group B. It was hypothesised that the sexual activity of the submerged specimens, living close to the soft bottom, could be influenced by severe anoxic crises due to periodic algal decay, whereas the intertidal specimens, located some decimetres off the soft bottom, and subjected to the moderate water movement, were not affected. The thick algal assemblage associated with the intertidal specimens gives protection against dehydration and solar irradiation during the prolonged periods of air exposure. By September, none of the monitored specimens had survived. The finding of newly developing small specimens in late winter supports a possible colonisation from residual sponge fragments dispersed before mass mortality.
\end{abstract}

Keywords: Sponge, hymeniacidon perlevis, reproduction, Ionian sea, temperature, fragmentation.

\section{INTRODUCTION}

The monoaxonid sponge Hymeniacidon perlevis (Montagu, 1818) is a suitable species for investigating several aspects of sponge biology, because it is common and abundant along coastlines providing abundant material to work with [1]. From an ecological perspective, H. perlevis has been shown to be a remarkable potential bioremediator, which is able to remove pathogenic bacteria from the cultured media, by retaining and digesting them by phagocytosis [2].

In the field of biotechnology, H. perlevis was considered as a model system for the synthesis of sponge-derived bioactive metabolites. In fact, many antibacterial and antitumoural compounds have been isolated from this sponge [3] and even their associated actinobacteria are considered as a promising source of the compounds of interest in biomedicine [4]. In order to produce sponge biomass that can be used as pharmaceutical potential, three-dimensional aggregates, and named primmorphs (multicellular aggregates from dissociated mixed-cell population) have been successfully used $[5,6]$. In $H$. perlevis, it has been proved that the addition of totipotent archaeocytes leads to be more stable primmorphs, thus suggesting a new method for the establishment of sponge cell culture in vitro [7].

\footnotetext{
*Address correspondence to this author at the Dipartimento di Biologia Cellulare e Ambientale - Università degli Studi di Perugia; Tel: 0755855702; Fax: 0755855733; E-mail: gaino@unipg.it
}

Recently, in order to develop methods for artificial seed production and sustainable supply in sponge aquaculture, $H$. perlevis has been the focus of an intensive study, and it focused on larval release and settlement under controlled condition [8].

There is progressively a more interest in investigating sponge reproduction, not only for the biological relevance per se but also for contributing information that can be used in the context of applied research $[9,10]$.

Exhaustive data on the reproduction of $H$. perlevis was reported by Stone [11] regarding an England population living in Langstone Harbour, by examining the presence of embryos in specimens and the larval settlement on suspended plates. In this habitat, the sponge population is essentially maintained by fragmentation, a process supported by the high regenerative properties of the sponge, rather than by sexual reproduction. The sexual cycle of $H$. perlevis, under the name of $H$. caruncula, was also investigated by Diaz [12] in the Thau pond. In this environment, this hermaphroditic species, showed a successive hermaphroditism in which oogenesis preceded spermatogenesis. Further information on this species can be found in Sarà [13] and Juniper and Steele [14].

The aim of our study was to investigate sexual reproduction in two groups of $H$. perlevis specimens, one of them subjected to sea level fluctuations, thus leading to frequent air exposure. The study was carried out in order to trace the main reproductive steps and ascertain, that how sponges behave when continuously or partially submerged. 


\section{MATERIAL AND METHODOLOGY}

\section{Studied Species}

Hymeniacidon perlevis, family Halichondriidae Gray, 1867 is represented by typically orange to red specimens, varying from encrusting to massive in shape. Short papillae and small digitations emerging from the sponge surface. Spicules and spicule bundles are made up of slightly curved styles, often with a faint tylote swelling subterminally [15]. The sponge has a wide distribution, it is viviparous and can be considered as cosmopolitan $[3,11,16]$. Ova are fertilised in the sponge body, where they give rise to ciliated larvae [17] of the parenchymella type. In the Portsmouth area, $H$. perlevis has been reported to be abundant in the summer [14] with a seasonal variation in growth and population size [11].

\section{Study Site}

Specimens of $H$. perlevis were collected from the Mar Piccolo di Taranto, which is an inner sea located at the North of the Gulf of Taranto (Ionian Sea). It comprises two distinct basins, the innermost of which receives inflow from some small streams. At the study site, water temperature varies from $8.4^{\circ} \mathrm{C}$ (December) to $26.8^{\circ} \mathrm{C}$ (August) [18]. Salinity values are around 36\% [18]. Locally, however, continental inflows may result in a marked drop of salinity (25-30\%o) (Corriero et al., unpublished data). Dissolved Oxygen shows a wide seasonal variability: the severe Oxygen deficit, usually occurring from May to October, is responsible for large mortality events $[18,19]$.

The studied area is located in this innermost basin (latitude N 40 $29^{\prime} 07^{\prime \prime}$, longitude E $\left.17^{\circ} 16^{\prime} 39^{\prime \prime}\right)$, and consists of a pile of calcareous stones, of varied sizes and shapes, some of which are seasonally subjected to long emersion periods, combined with the hydrometric syzygial variations of the sea level. The pile of stones lies over a silt bottom, often subjected to anoxic crises due to the deposition of large amount of vegetal detritus.

\section{Sampling Methods}

Sponges were subdivided in to two groups, named A and $\mathrm{B}$, each comprising ten specimens. The sponges in group A were subjected to periodical emersion, whereas those in group B were continuously submerged.

To estimate the relevance of sexual reproduction, monthly samplings, from February 2006 to January 2007, were taken from ten sponge specimens belonging to group A and B, respectively. Fragments of about $3 \mathrm{~cm}^{3}$ were cut from each tagged specimen, well distanced from one another, and fixed for 24 hours in $4 \%$ formaldehyde in filtered sea-water used as buffer, repeatedly washed in the same buffer, dehydrated in the crescent alcohol series and paraffin embedded.

For histological observations, $7 \mu \mathrm{m}$ sections were cut from the paraffin blocks by means of a Rotary One microtome, and then processed according to the routinely used methodology for setting up stable preparations. Sections were stained with toluidine blue and observed under a light microscope (Olympus $\mathrm{BH} 2$ ). The water temperature values and salinity were measured at every sampling interval using a multiparametric probe (OCEAN Seven 316 Plus).

During the monitoring period, the aerial exposure of the specimens was calculated by recording the value of the water level on the sponge and that of the tide intensity. In order to obtain the oscillations of the water level with respect to each specimen, the data was compared to the tide trend recorded by the tide gauge located in Mar Grande (Taranto) (data from ISPRA).

The quantitative evaluation of the reproductive elements was performed using Abercrombie's formula [20].

Univariate statistical analysis (mean $\pm \mathrm{SD}$ ) was limited to reproductive specimens. Differences in the frequency of reproductive specimens and in the density of sexual elements between group A and B sponges were evaluated by applying the non-parametric Chi-square test.

Furthermore, for group A, the correlation between the frequency of days in which the sponges were subjected to aerial exposure and reproductive effort (frequency of reproductive specimens, density of sexual elements) was analyzed with the Spearman $\left(r_{\mathrm{s}}\right)$ test.

Finally, the relationships between reproductive parameters, water temperature and salinity were calculated using the Spearman $\left(r_{\mathrm{s}}\right)$ coeffcient of correlation.

\section{RESULTS}

Fig. (1) shows the monthly variation in water temperature and salinity from the study site. Field observations allowed us to study sexual reproduction and other aspects of the life cycle of the monitored Hymeniacidon perlevis specimens

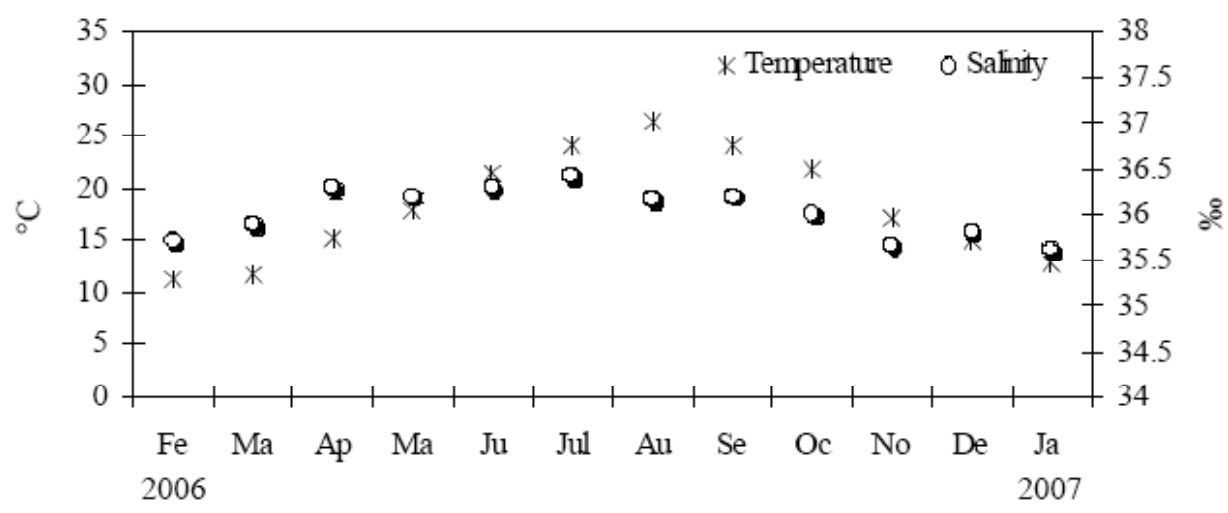

Fig. (1). Monthly variation of water temperature and salinity at the study site. 
which live in an unpredictable environment having characteristics typical of the intertidal zone.

The monthly presence of the reproductive elements in the twenty labelled specimens was schematized in Fig. (2).

Sponge reproduction started in April, in parallel with increased temperature (Fig. 1), and fertile sponges could be detected until September. In the following months, the specimens were not observed further, in spite of the repeatedly surveys carried out up to January. In April, earlystage oocytes of $20-30 \mu \mathrm{m}$ in diameter were evident as amoeboid cells scattered in the mesohyl. They have an irregular perimeter, a granular cytoplasm and a nucleolate nucleus (Fig. 3a). As the oogenesis progresses, the oocytes gradually became surrounded by a layer of follicle cells which increased in thickness according to the maturation phases (Fig. 3b). Nurse cells are external to the oocyte membrane although located in invaginations of the oocyte (Fig. 3c). In May, oocyte growth led to mature elements measuring about $100 \mu \mathrm{m}$. The maturation process took place asynchronously, both in a single specimen and among specimens, in such a way that young oocytes tended to coexist with the mature ones. This condition persisted until August, despite the number of fertile specimens gradually diminishing.

Spermatic cysts occurred in May and the male presence reached its peak in June (Fig. 2). Different phases of gamete

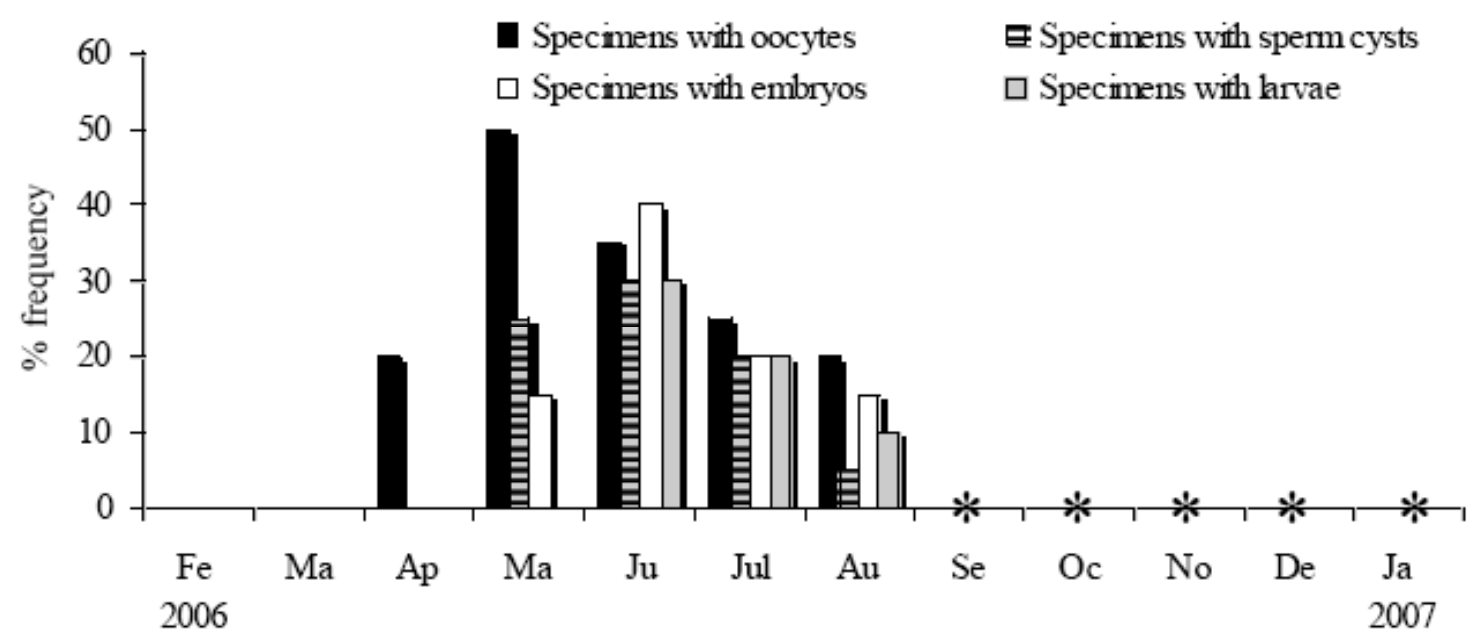

Fig. (2). Hymeniacidon perlevis - Monthly frequency of specimens with oocytes, sperm cysts, embryos and larvae; * specimen death.
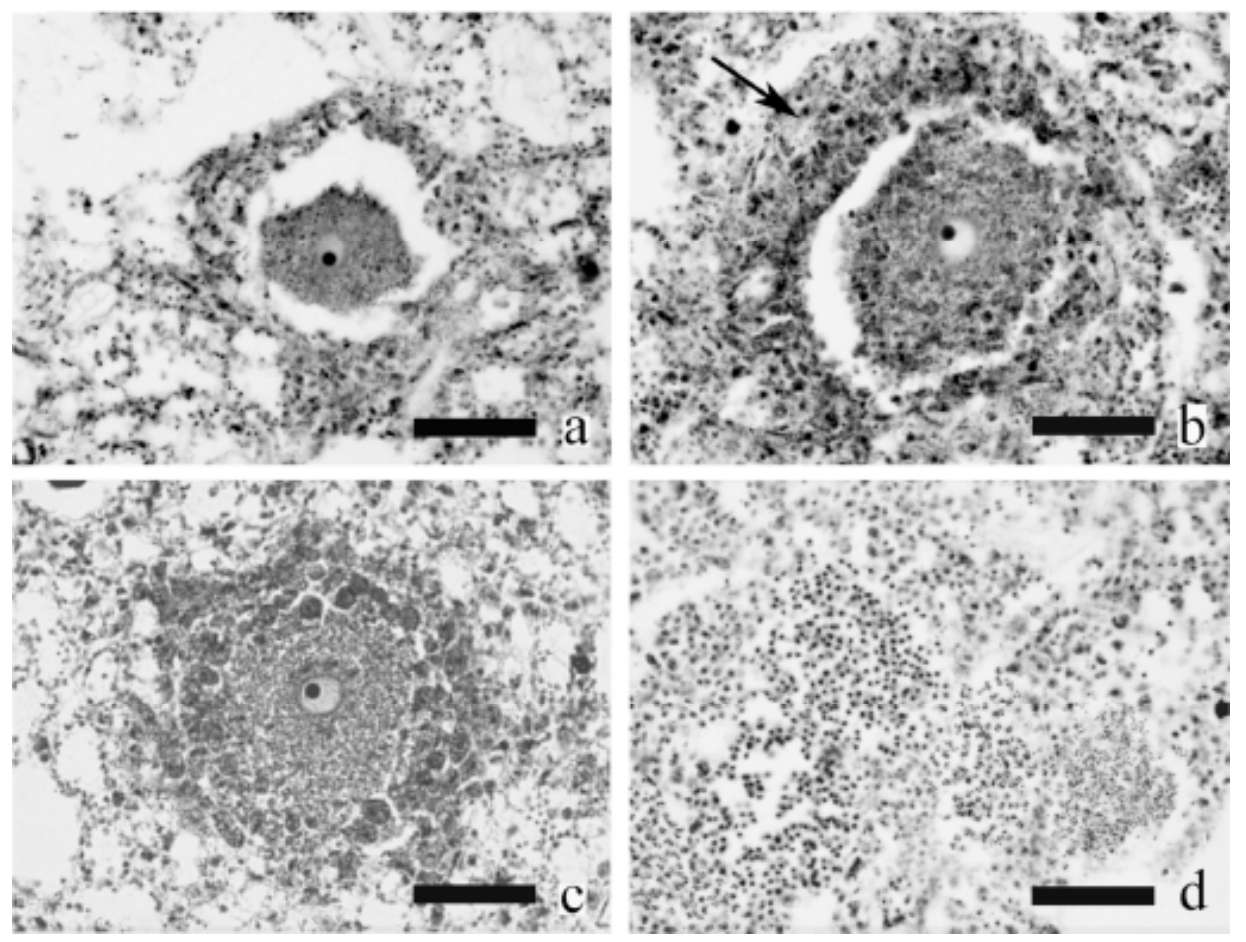

Fig. (3). Hymeniacidon perlevis - Histological sections showing the reproductive elements. a) Oocyte in the early phase of differentiation $($ bar $=20 \mu \mathrm{m})$. b) Growing oocyte surrounded by follicle cells (arrow) (bar $=30 \mu \mathrm{m})$. c) Follicle cells located in invaginations of the oocyte $(\mathrm{bar}=50 \mu \mathrm{m})$. d) Spermatic cyst in the choanosomal region. Different cysts contain sperm in various phases of differentiation $(\mathrm{bar}=50 \mu \mathrm{m})$. 

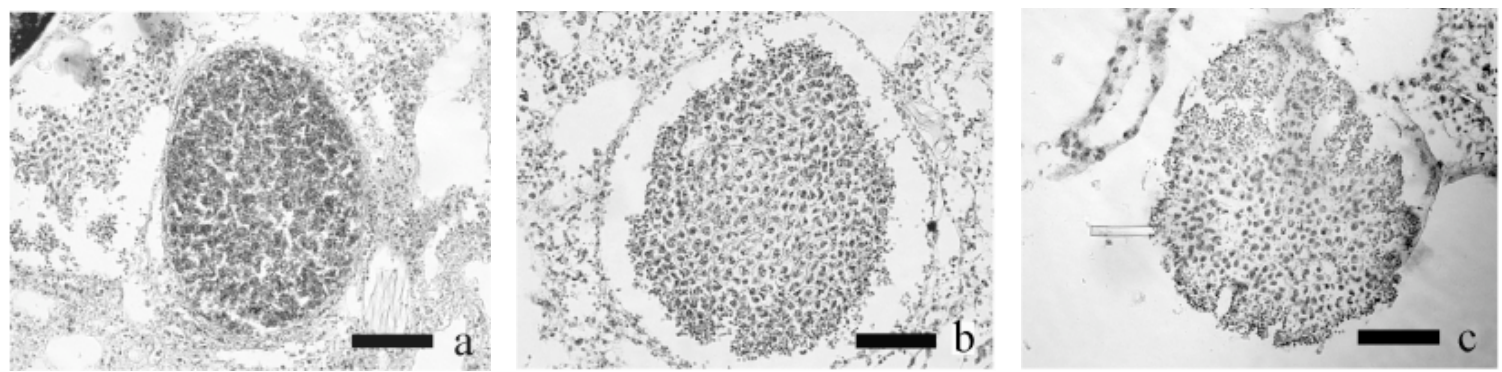

Fig. (4). Hymeniacidon perlevis - Histological sections showing the reproductive elements. a) Embryo (bar $50=\mu \mathrm{m})$. b) Stereoblastula larva (bar $50=\mu \mathrm{m})$. c) Parenchymella larva (bar $=50 \mu \mathrm{m})$

differentiation coexisted in a specimen (Fig. 3d). The number of male specimens decreased in July and August.

Embryos (Fig. 4a) were firstly observed in May, although specimens carrying embryos were very limited
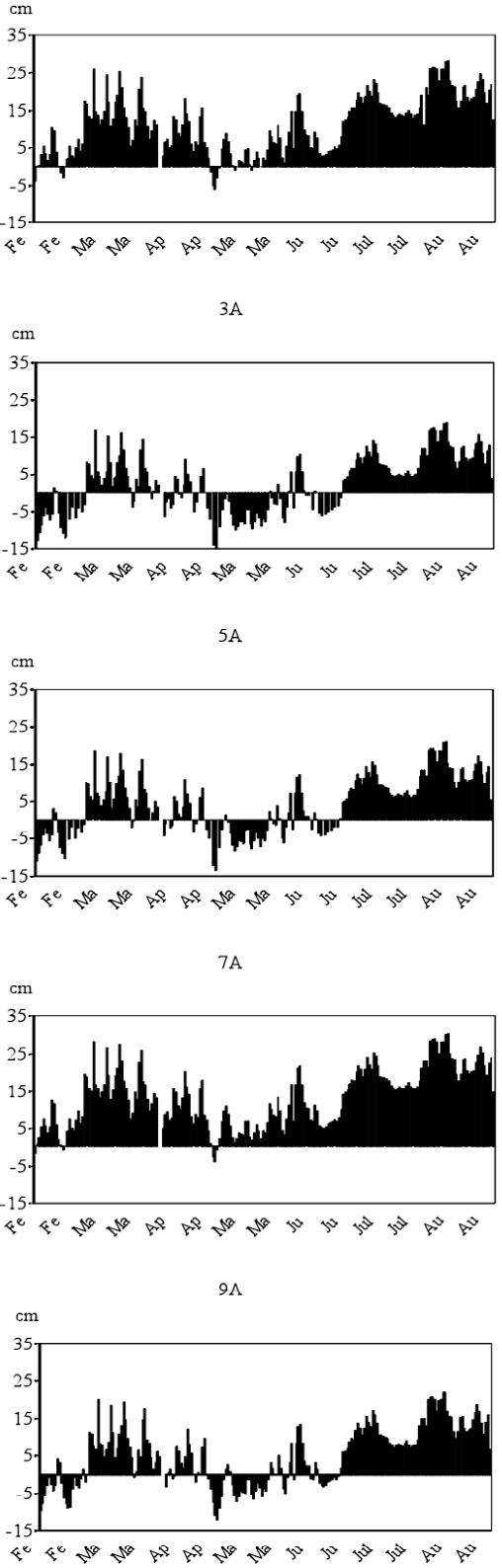

(Fig. 2). The number of these sponges reached a peak in June, and decreased in the following months.

Stereoblastula larvae, as solid elements with maximum diameter of about $200 \mu \mathrm{m}$, showing a typical segregation
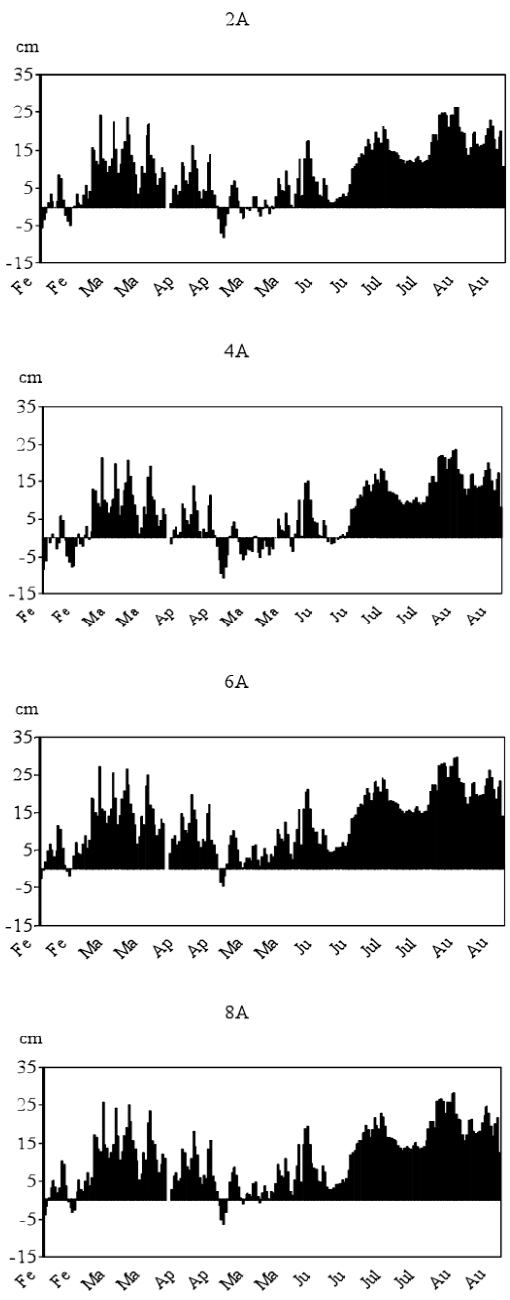

$10 \mathrm{~A}$

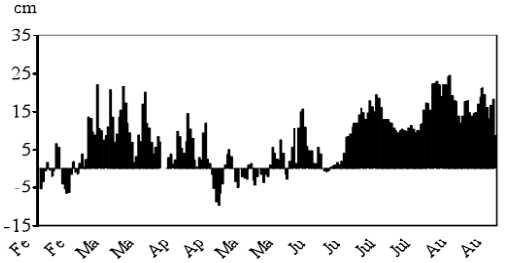

Fig. (5). Hymeniacidon perlevis - Mean values of sea level for each sampled specimen during the study period. 
between peripheral non-flagellated cells and the more rounded internal cells (Fig. 4b), were first observed in June where sponges bearing this larval stage reached their maximum level (Fig. 2). In the mesohyl, among the stereoblastula larvae, only a few mature parenchymellae, having a maximum diameter of about $250 \mu \mathrm{m}$, were also distinguishable for their uniform covering of flagellated cells and numerous folds along the outermost larval surface (Fig. 4c). Therefore, the peak, even though it mainly consisted of specimens with stereoblastulae, also included a few parenchymellae. In addition, specimens with stereoblastulae were also observed in July and August.

The positive relationships between the density of sexual elements and water temperature (oocytes: $r_{\mathrm{s}}=0.29$; sperm cysts: $r_{\mathrm{s}}=0.15$; embryos: $r_{\mathrm{s}}=0.34$; larvae: $\left.r_{\mathrm{s}}=0.43\right)$, and between the density of sexual elements and salinity (oocytes: $r_{\mathrm{s}}=0.33$; sperm cysts: $r_{\mathrm{s}}=0.31$; embryos: $r_{\mathrm{s}}=0.3$; larvae: $r_{\mathrm{s}}=0.26$ ) were significant (Spearman $\left(r_{\mathrm{s}}\right)$ coeffcient of correlation, $P<0.01)$.

\section{Reproduction of Group A, Represented by Periodically Emerged Specimens}

Over time, each specimen was affected by different periods of air exposure due to sea level oscillations, as reported in the Fig. (5). Among the monitored specimens, the more superficial sponge (no. 3A) was completely intermingled with macroalgae, and was repeatedly subjected to emersion periods leading to a complete exposure of the sponge to the air.
Fig. (6) shows the trend of the mean monthly density and the mean size of the reproductive elements for group A. The reproductive activity of each of the ten monitored specimens is shown in Fig. (7).

During the study period, nine out of ten sponges were fertile and eight were found to be gonochoric: three males (specimens no. 1A, 9A, 10A) and five females (specimens no. 2A, 5A, 6A, 7A, 8A); one was hermaphroditic (specimen no. 4A) (Fig. 7).

In the six sponges producing oocytes (five plus the hermaphrodite) the reproductive effort and periodicity were different, and only specimen no. 6A sustained oogenesis from April to August, whereas the remaining ones restricted female gametogenesis to a short period. The specimen no. $5 \mathrm{~A}$ only had gamete differentiation in May.

On the whole, maximum density and oocyte diameter values were recorded in May $\left(39.9 \pm 14.38\right.$ per $\mathrm{mm}^{3}$ and $71.51 \pm 5.52 \mu \mathrm{m}$ respectively) (Fig. 6a). In parallel with the maximum size of the oocytes in May, spermatic cysts became evident. They persisted until July with a mean density of 19.37 (Fig. 6b).

Among the four sponges producing sperm cysts (three gonochoric plus the hermaphroditic specimens), the longest period of spermatogenesis was observed in specimen no. 9A (from May to July) whereas in no. 10A, it occurred in May and June, and in no. $1 \mathrm{~A}$ it was restricted to June. The hermaphroditic no. 4A showed sperm cysts only in May. In this sponge, male and female gametes were not simultaneous present (Fig. 7). a

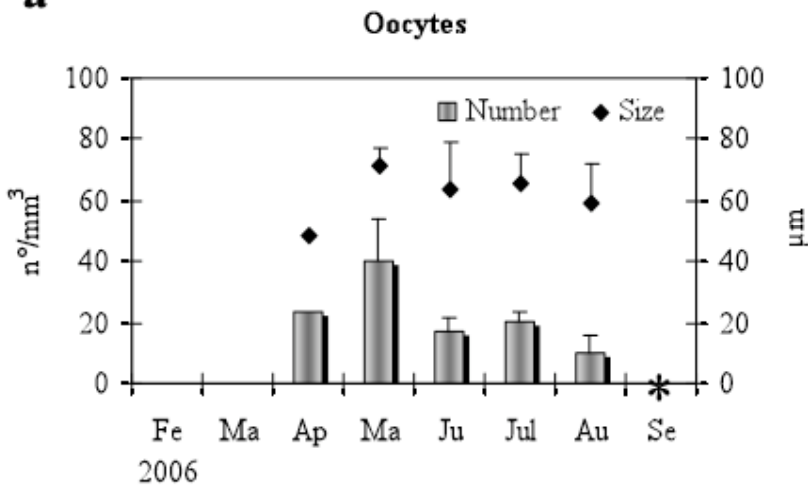

c

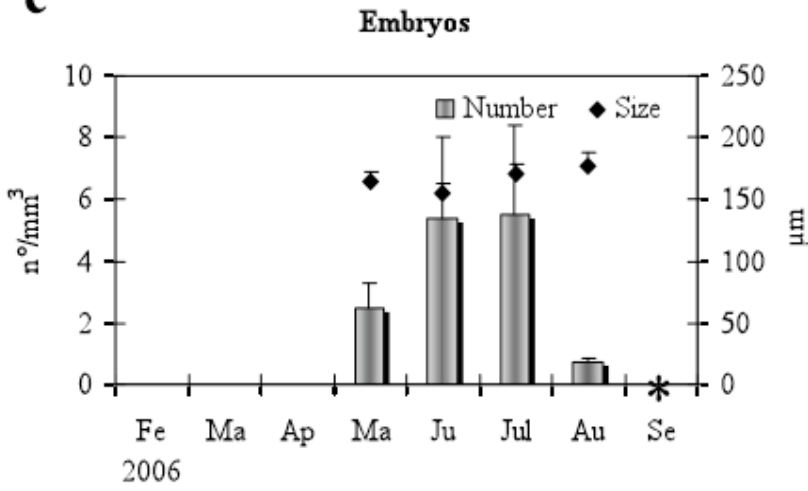

b

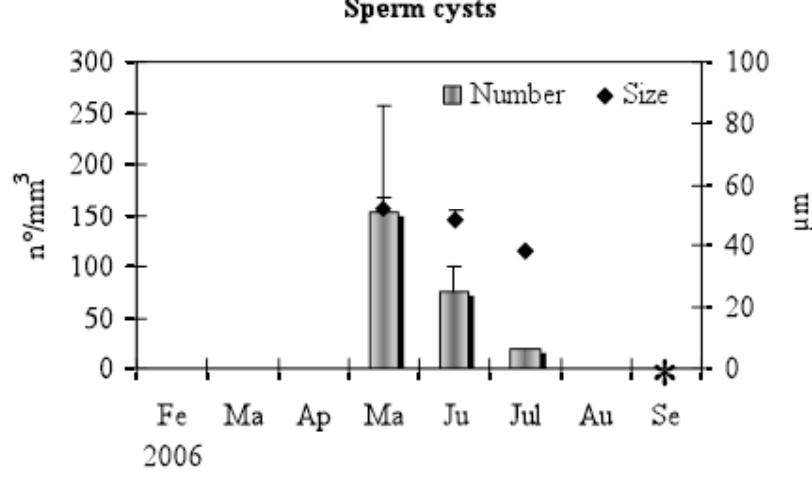

d

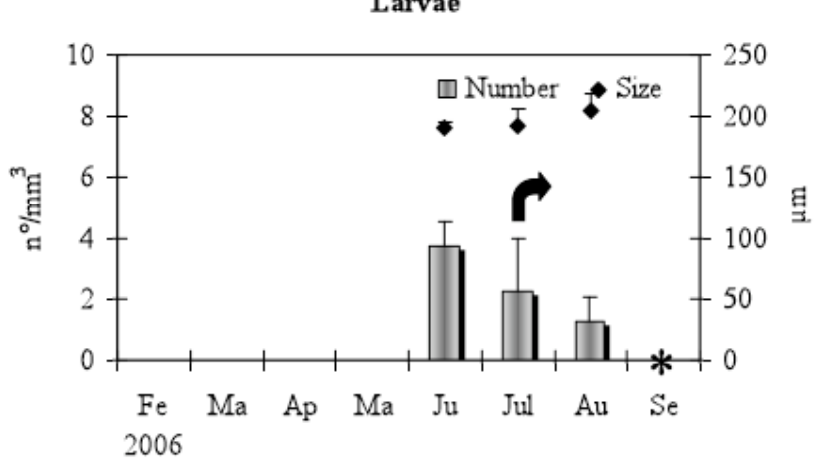

Fig. (6). Hymeniacidon perlevis - Group A - monthly mean size and number of oocytes (a), sperm cysts (b) embryos (c) and larvae (d) per $\mathrm{mm}^{3}$ of sponge tissue ( \pm standard error). Arrow indicates the larval release; $*$ specimen extinction. 
1A

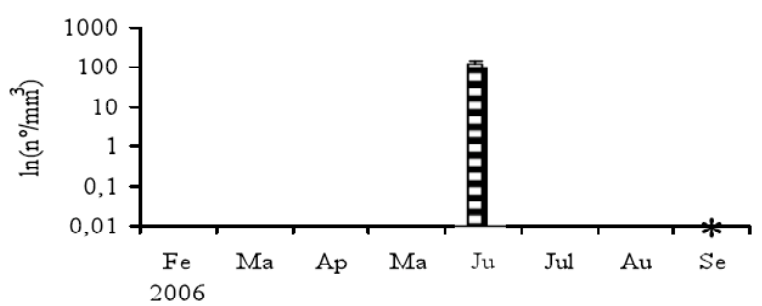

4A

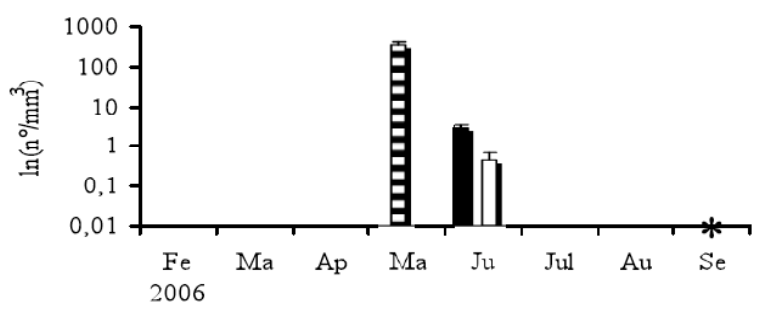

$6 \mathrm{~A}$

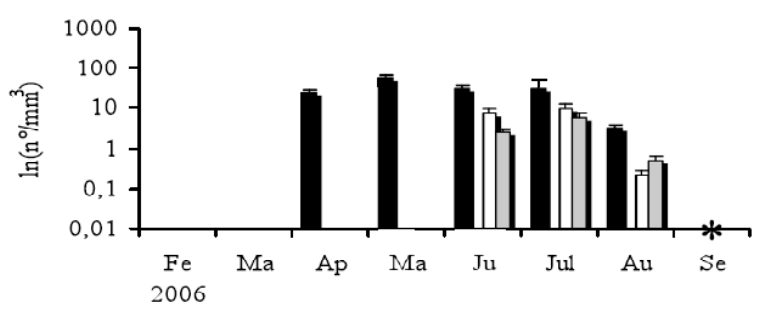

$8 \mathrm{~A}$

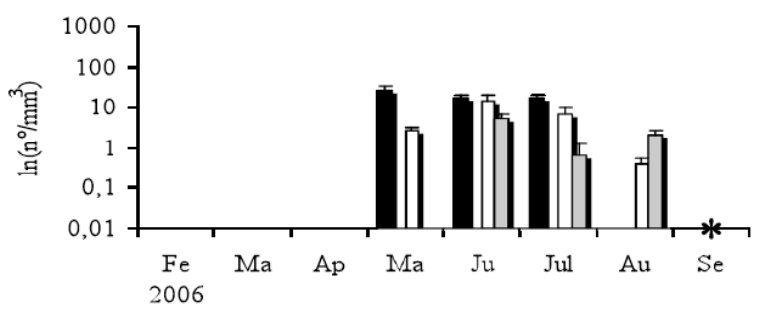

$10 \mathrm{~A}$

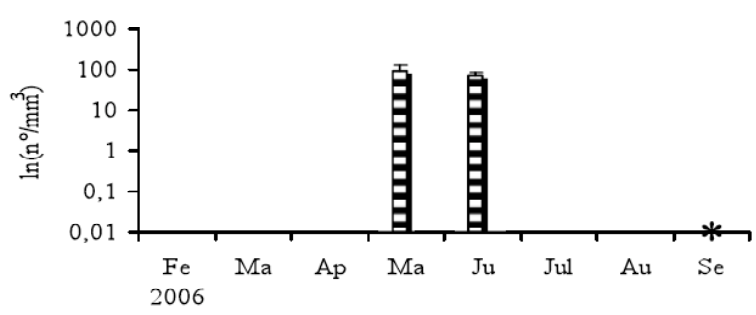

2A

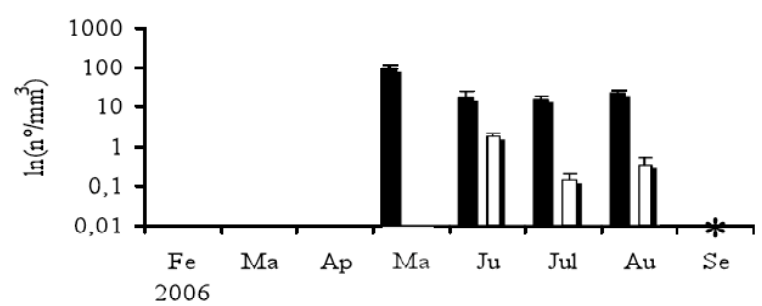

$5 \mathrm{~A}$

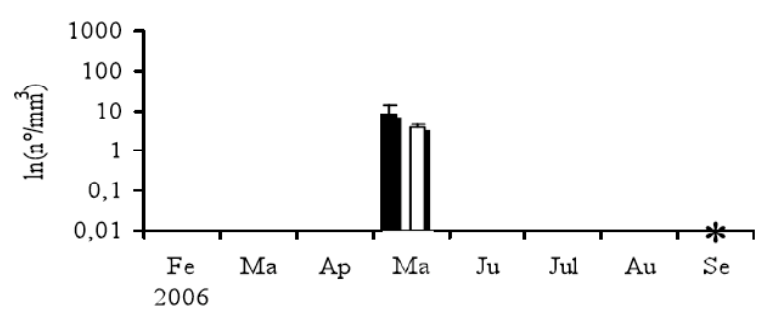

7A

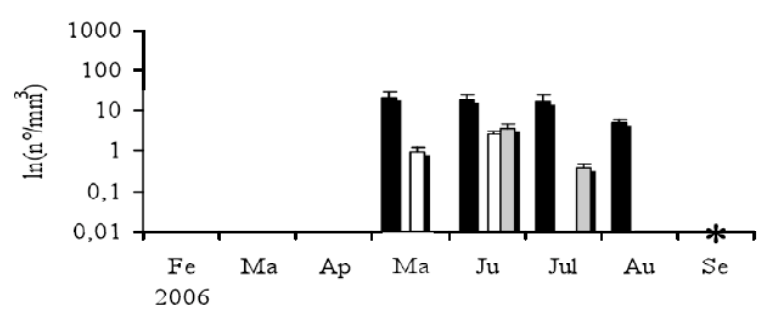

9A

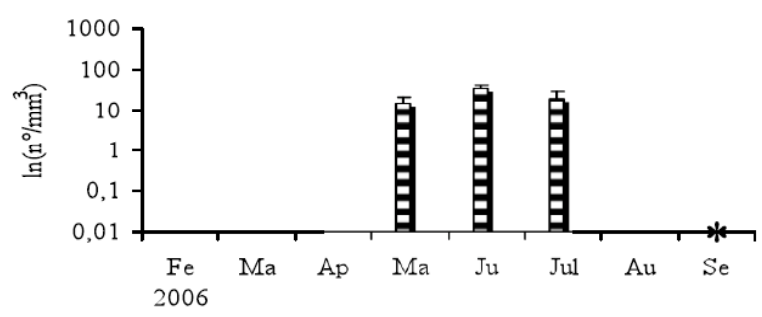

- Oocytes

E Sperm cysts

$\square$ Embryos

$\square$ Larvae

Fig. (7). Hymeniacidon perlevis - Sexual abundance trend (mean monthly number of oocytes, sperm cysts, embryos and larvae per mm ${ }^{3}$ of sponge tissue) for each monitored specimen of the group $\mathrm{A} ; *$ specimen extinction.

The peak density (mean values) of embryos was recorded in June and July $\left(5.38 \pm 2.59\right.$ and $5.55 \pm 2.8$ per $\mathrm{mm}^{3}$, respectively). The embryos size varied from 160 to $180 \mu \mathrm{m}$ (Fig. 6c). As for the oocytes, the presence of the embryos differed according to the different specimens. The occurrence of embryos was first observed in May (specimens no. $5 \mathrm{~A}, 7 \mathrm{~A}, 8 \mathrm{~A})$ and in June in the remaining sponges (specimens no. 2A, 4A, 6A) (Fig. 7).

The maximum density $\left(3.74 \pm 0.77\right.$ per $\left.\mathrm{mm}^{3}\right)$ of larvae was recorded in June when both stereoblastulae and parenchymellae were present (Fig. 6d). A complete differentiation 
a

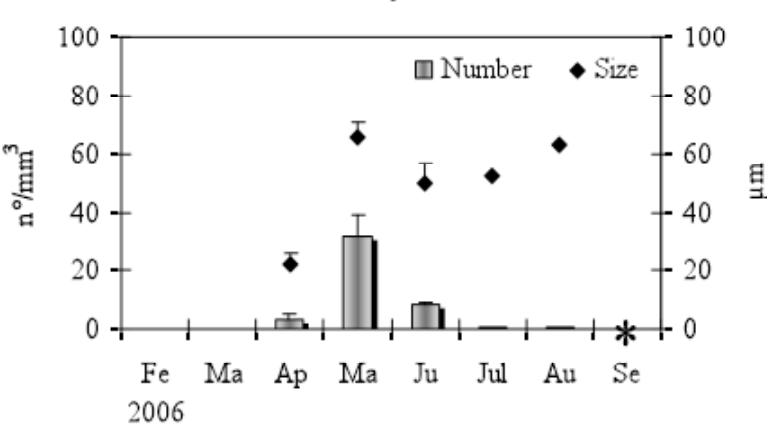

C

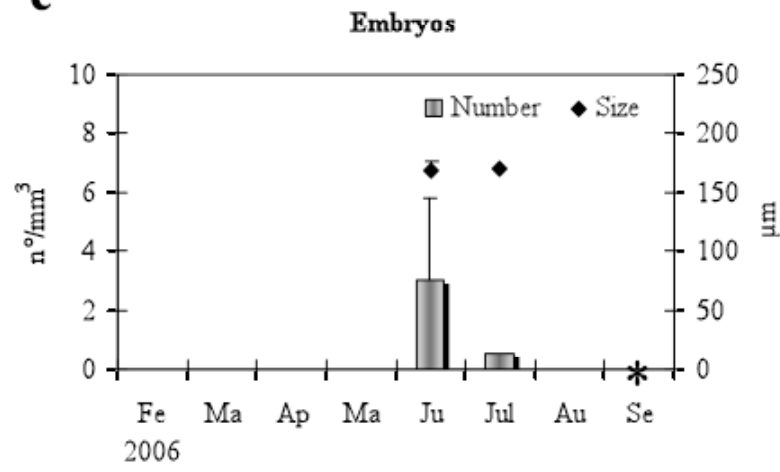

b

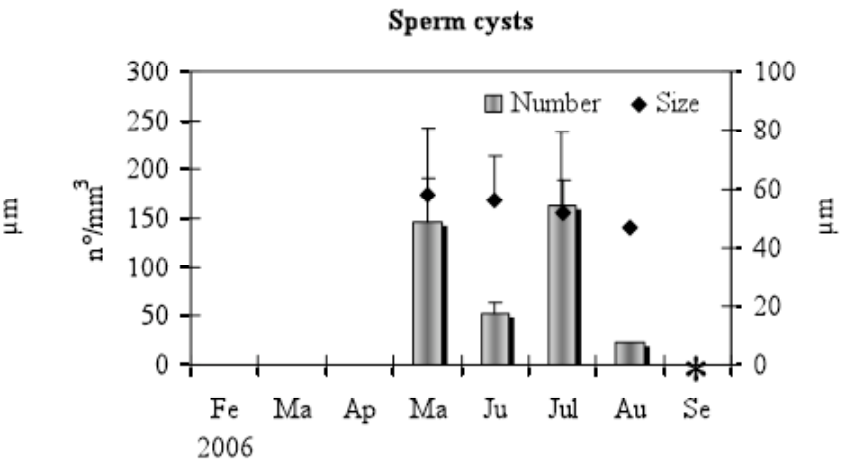

d

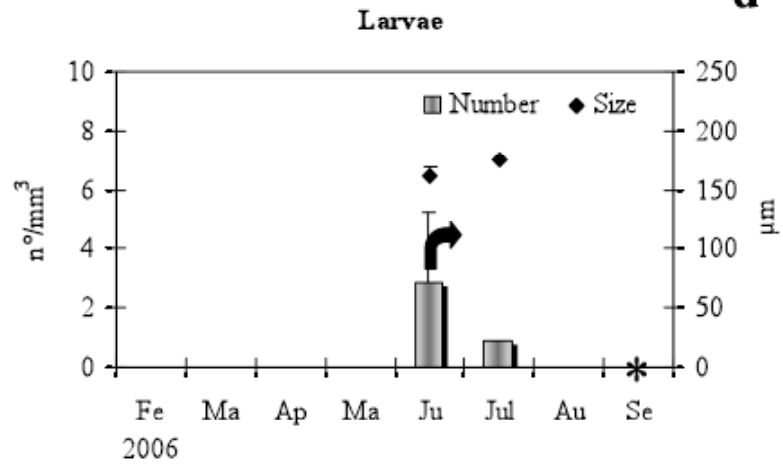

Fig. (8). Hymeniacidon perlevis - Group B - monthly mean size and number of oocytes (a), sperm cysts (b) embryos (c) and larvae (d) per $\mathrm{mm}^{3}$ of sponge tissue ( \pm standard error). Arrow indicate the larval release; * specimen extinction.

from oocytes to larvae was observed in three (no. 6A, 7A, $8 \mathrm{~A}$ ) out six sponges (Fig. 7). The negative correlations between the density of sexual elements and the frequency of days in which the sponges were subjected to air exposure (oocytes: $r_{\mathrm{s}}=-0.53$; sperm cysts: $r_{\mathrm{s}}=-0.2$; embryos: $r_{\mathrm{s}}=-0.31$; larvae: $\left.r_{\mathrm{s}}=-0.75\right)$ were not significant for the Spearman $\left(r_{\mathrm{s}}\right)$ test.

\section{Reproduction of Group B, Represented by Continuously Submerged Specimens}

Fig. (8) shows the trend of mean monthly density and size of reproductive elements for group B sponges. The reproductive activity of each of the ten monitored specimens is shown in Fig. (9). During the study period, nine out of ten sponges were fertile and eight were found to be gonochoric: three males (specimens no. 1B, 3B, 7B) and five females (specimens no. 2B, 4B, 8B, 9B, 10B); one was hermaphroditic (specimen no. 6B) (Fig. 9).

Like the oocytes in group A, maximum density and oocytes diameter value of the group B was recorded in May $\left(31.5 \pm 7.79\right.$ per $\mathrm{mm}^{3}$ and $65.92 \pm 5.07 \mu \mathrm{m}$ respectively) (Fig. 8a).

In the six sponges producing oocytes (five plus the hermaphrodite) the reproductive effort and periodicity were different. Specimen no. 2B sustained oogenesis from April to June, no. 9B from June to August, whereas the remaining sponges had restricted female gametogenesis to one (hermaphroditic and no. 10B) or two (no. 4B and 8B) months (Fig. 9).
Regarding sperm cysts, two density peaks occurred in May and July with a density value of $146 \pm 95.69$ and $162.58 \pm 75.82$ respectively (Fig. 8b). Among the four sponges producing sperm cysts, the longest period of spermatogenesis was observed in specimen no. 7B (from May to July), whereas the remaining ones had sperm cysts for two months. In particular, specimen no. 1B ended spermatogenesis in August. The hermaphroditic no. 6B also showed sperm cysts for two months (from June to July). In this sponge male and female gametes are not simultaneously present (Fig. 9).

The occurrence of embryos was limited to June (specimens no. 8B-10B) and July (specimen no. 2B) with a mean density of $3 \pm 2.76$ and 0.58 per $\mathrm{mm}^{3}$ respectively (Fig. 8c).

The months and the sponges with larvae (stereoblastula plus parenchymella) were the same as those recorded for the embryos (Fig. 8d). Parenchymella larvae were only found in June. Larvae (stereoblastula plus parenchymella) were detected in four (no. 2B, 8B, 9B, 10B) out of six sponges. Generally, larval phases were found in only one month starting from June (Fig. 9).

\section{Comparative Analysis of Sexual Reproduction in the Groups A and B}

The frequency of specimens with oocytes, sperm cysts, embryos and larvae, did not vary significantly between the two groups. The mean density values of oocytes and embryos, during all the months of their occurrence were significantly higher in group A $(P<0.01)$. Larval density was 
1B

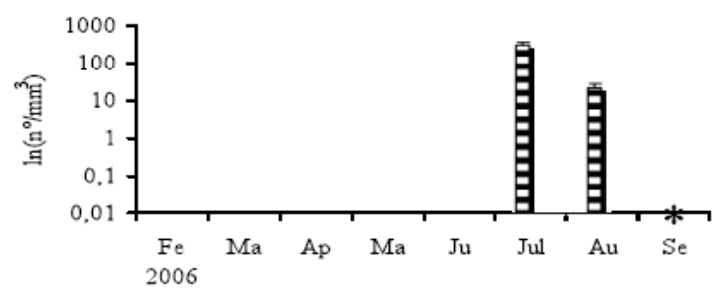

3B

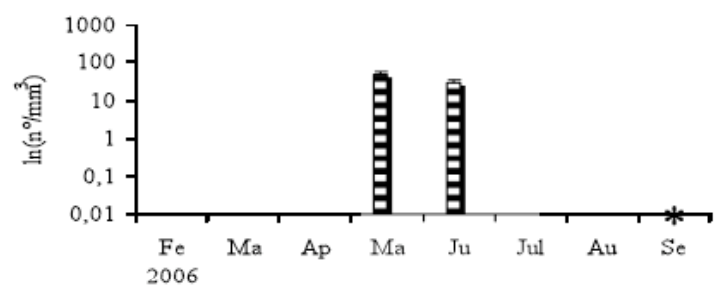

$6 \mathrm{~B}$

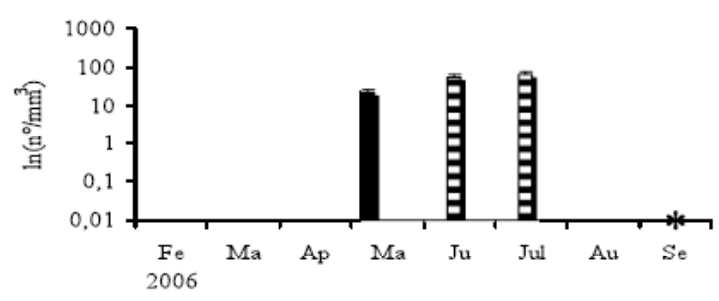

8B

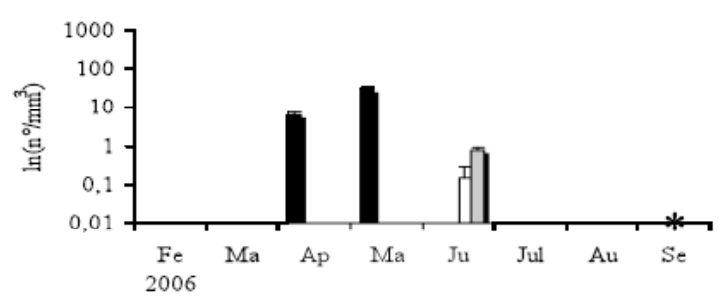

$10 \mathrm{~B}$

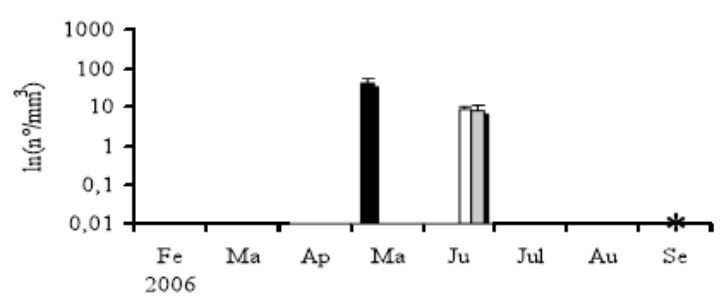

2B

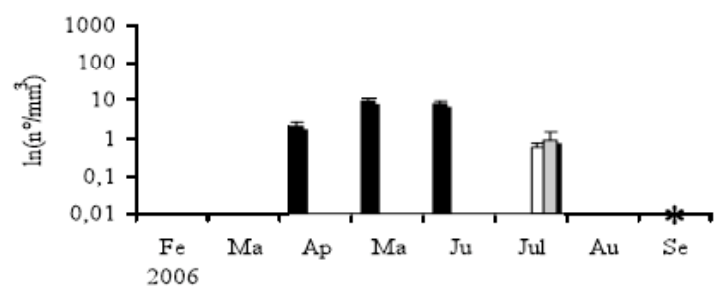

4B

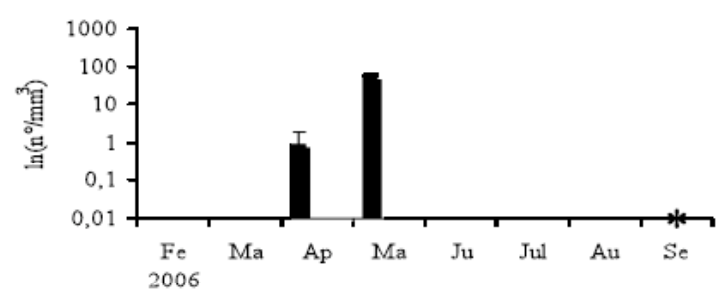

7B

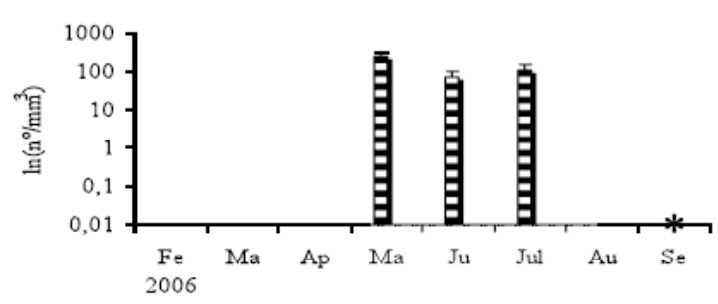

9B

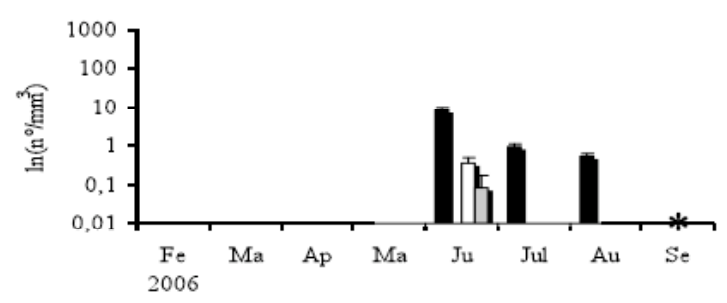

- Oocytes

I Sperm cysts

口Embryos

口Larvae

Fig. (9). Hymeniacidon perlevis - Sexual abundance trend (mean monthly number of oocytes, sperm cysts, embryos and larvae per mm ${ }^{3}$ of sponge tissue) for each monitored specimen of the group B; * specimen extinction.

also higher in group A, but differences were not significantly different. By contrast, the mean density of sperm cysts was significantly higher in the continuously submerged specimens (group B).

\section{DISCUSSION AND CONCLUSION}

Sponges use a variety of strategies for reproduction including sexual and asexual processes [9]. In this regard,
Hymeniacidon perlevis, in a similar manner to other demosponges [21,22] takes advantages of both mechanisms [11].

Based on the presence of degenerating oocytes in some male specimens, Sarà [13] hypothesized that, in spite of a typical gonochoric condition, $H$. perlevis (former $H$. sanguinea) could be potentially hermaphroditic. The hermaphroditic specimens collected in Mar Piccolo di Taranto confirmed the possibility of a shift from gonochorism to a 
successive hermaphroditism, a situation probably linked to the unbalanced sex ratio, with a female overabundance. Nevertheless, in Spongia officinalis, it has been observed that, in spite of a sex ratio $1: 1$, nine gonochoric specimens coexisted with one single hermaphroditic specimen [23].

The onset of gametogenesis seems to be triggered by environmental parameters, amongst which the water temperature constitutes the most relevant factor, according to statistical analyses [22, 24, 25]. As reported by Diaz [12], in $H$. perlevis, an increase in water temperature causes female gamete differentiation, which precedes the presence of sperm cysts by one month.

At the Mar Piccolo di Taranto, given that the differentiation and growth of the sexual elements is asynchronous, the reproductive timing lasts five months for the females and three months for the males. Therefore, the larval release may take place gradually as corroborated by the co-existence of stereoblastula and parenchymella larvae in June and of stereoblastulae in the following months (July and August). Likewise, this asynchronous event was previously confirmed under controlled laboratory conditions [8].

On the whole, the reproductive process in the monitored specimens is limited to five months, from the end of spring to the late summer. Afterwards, the sponges disappeared. Field observations carried out for an additional five months, up until the late winter 2007, did not detect sponge recovery (Cardone, personal observations).

Sponges living in habitats subjected to marked variations in environmental parameters often split into fragments or fuse together [26-28], a process stressing the remarkable plasticity of these organisms, which represents a strategy for survival and spreading [29]. This plasticity is able to control population dynamics and spatial interaction among species, as recently remarked by Bell [30] who confirmed previous observations $[11,31,32]$ about the seasonally available space due to sponge tissue contraction periods.

Notwithstanding this plasticity, sponges may be affected by massive mortality that drastically reduces the population density $[27,33]$. In this regard, the mortality of $H$. perlevis observed at Taranto, led to the disappearance of all the monitored specimens. However, the finding of new specimens in late spring leads us to hypothesise that a process of re-colonisation took place, probably starting from undetectable small residual fragments. Sponge survival as minute bodies derived from fragmentation has been also described in a calcareous sponge, allowing it to withstand summer crisis [34]. Therefore, sponge fragmentation represents a mechanism not only for enhancing the asexual colonisation but also for increasing genetic variability when sexual elements are included in such propaguli [35].

The comparison between the specimens of $H$. perlevis belonging to groups $\mathrm{A}$ and $\mathrm{B}$, respectively characterised by periodically emerged and by continuously submerged specimens, allowed us to hypothesize about the role of marked variations in environmental parameters on the sponge reproductive process and mortality. Beyond expectation, the specimens in group B had lower reproductive effort, which probably reflects a highly stressed condition. These sponges, in fact, which inhabited the lower portion of the stones, were a few centimetres above a soft bottom, and are subjected to frequent anoxic events mainly due to periodical depositions of high quantities of algal detritus [36]. This phenomenon led to a strong reduction of the available oxygen, with a marked production of $\mathrm{H}_{2} \mathrm{~S}$ [37], as confirmed by the periodical occurrence of a black layer covering the basal part of the hard substrata, a situation which would have affected the vital functions, as well as the reproductive efficiency of the sessile animals living in proximity to the anoxic layer.

By contrast, the specimens in group A, located some decimetres from the soft bottom, and subjected to a certain degree of water movement due to low wave action and to moderate tidal currents [38], showed a reproductive element density significantly higher than those in group B, exhibiting a marked tolerance to air exposure. It is well known that $H$. perlevis grows around algae which become incorporated, thus giving rise to a commonly observed sponge/alga interaction, even though the nature of this phenomenon is difficult to interpret [30]. It seems acceptable that the occurrence of a thick layer of macroalgae in the specimens of $H$. perlevis could provide a way to helping the sponge prevent dehydration during air exposure. In such a way, the high water retention occurring in the algal tissue, due to a large amount of agar products, could contribute to preserving the dampness within the sponge-algal association. This may allow the sponge to better support sexual reproduction up to larval release.

In conclusion, the intertidal species $H$. perlevis showed a peculiar adaptive strategy allowing sponge to face aerial exposure at low water. This main stress factor does not interfere with the metabolic activity or sexual reproduction, which is restricted to the months that precede mass mortality events. Over time, we cannot exclude the possibility that released parts of the decaying specimens may contribute to re-building the population.

\section{REFERENCES}

[1] Stone AR. Seasonal variation in the gross biochemical composition of Hymeniacidon perleve (Montagu). J Exp Mar Biol Ecol 1970a; 5: 265-71.

[2] Fu W, Sun L, Zhang X, Zhang W. Potential of the marine sponge Hymeniacidon perleve as a bioremediator of pathogenic bacteria in integrated aquaculture ecosystem. Biotechnol Bioeng 2006; 93: 1112-22.

[3] Xue S, Zhang HT, Wu PC, Zhang W, Yuan Q. Study on bioactivity of extracts from marine sponges in Chinese Sea. J Exp Mar Biol Ecol 2004; 298: 71-8.

[4] Zhang H, Lee YK, Zhang W, Lee HK. Culturable actinobacteria from the marine sponge Hymeniacidon perleve: isolation and phylogenetic diversity by $16 \mathrm{~S}$ rRNA gene-RFLP analysis. Anton Leeuw Int J G 2006; 90: 159-69.

[5] Custodio MR, Prokic I, Steffen R, et al. Primmorphs generated from dissociated cells of the sponge Suberites domuncula: a model system for studies of cell proliferation and cell death. Mech Ageing Dev 1998; 105: 45-59.

[6] Nickel M, Leininger S, Proll G, Brümmer B. Comparative studies on two potential methods for the biotechnological production of sponge biomass. J Biotechnol 2001; 92: 169-78.

[7] Zhang X, Cao X, Zhang W, Yu X, Jin M. Primmorphs from archaeocytes-dominant cell population of the sponge Hymeniacidon perleve: improved cell proliferation and spiculogenesis. Biotechnol Bioeng 2003; 84: 583-90.

[8] Xue L, Zhang X, Zhang W. Larval release and settlement of the marine sponge Hymeniacidon perlevis (Porifera, Demospongiae) under controlled laboratory conditions. Aquaculture 2009; 290: 132-9. 
[9] Maldonado M, Riesgo A. Reproduction in the phylum Porifera: a synoptic overview. Treballs de la SCB 2008; 59: 29-49.

[10] Maldonado M, Riesgo A. Gametogenesis, embryogenesis, and larval features of the oviparous sponge Petrosia ficiformis (Haplosclerida, Demospongiae). Mar Biol 2009; 156: 2181-97.

[11] Stone AR. Growth and reproduction of Hymeniacidon perleve (Montagu) (Porifera) in Langstone Harbour, Hamphire. J Zool London 1970b; 161: 443-59.

[12] Diaz JP. Cycle sexuel de deux demosponges de l'Étang de Thau: Suberites massa Nardo et Hymeniacidon caruncula Bowerbank. Bull Soc Zool France 1973; 98(1): 145-56.

[13] Sarà M. Ricerche sul gonocorismo ed ermafroditismo nei Poriferi. Boll Zool 1961; 28: 47-59.

[14] Juniper AJA, Steele RD. The intertidal sponges of the Portsmouth area. J Nat Hist 1969; 3: 153-63.

[15] Erpenbeck D, Van Soest RWM. Halichondriidae Gray, 1867. In: Hooper JNA, Van Soest RWM, Eds. Systema porifera. New York: Kluwer Academic Plenum Publishers 2002; pp. 787-815.

[16] Pansini M. Littoral demosponges from the banks of the Strait of Sicily and the Alboran Sea. In: Vacelet J, Boury-Esnault N, Eds. Taxonomy of Porifera from the N.E. Atlantic and Mediterranean Sea. NATO ASI Series 1987; Vol. G13: pp. 149-85.

[17] Levi C. Etudes des Halisarca de Roscoff. Embryologie et systematiques des Demosponges. Archs Zool Exp Gén 1956; 93: 1181.

[18] Caroppo C, Cardellicchio N. Preliminary study on phytoplankton communities of Mar Piccolo in Taranto (Jonian Sea). Oebalia 1995; 21(2): 61-76.

[19] Alabiso G, Cannalire M, Ghionda D, Milillo M, Leone G, Caciorgna O. Particulate matter and chemical-physical conditions of an inner sea: the Mar Piccolo in Taranto. A new statistical approach. Mar Chem 1997; 58: 373-38.

[20] Abercrombie M. Estimation of nuclear populations from microtomic sections. Anat Rec 1946; 94: 239-47.

[21] Corriero G, Sarà M, Vaccaro P. Sexual and asexual reproduction in two species of Tethya (Porifera, Demospongiae) from a mediterranean coastal lagoon. Mar Biol 1996; 126: 175-81.

[22] Corriero G, Scalera-Liaci L, Nonnis MC, Gaino E. Reproductive strategies of Mycale contarenii (Porifera: Demospongiae). Mar Biol 1998, 131: 319-27.

[23] Baldacconi R, Nonnis MC, Gaino E, Corriero G. Sexual reproduction, larval development and release in Spongia officinalis L. (Porifera, Demospongiae) from the Apulian coast. Mar Biol 2007; 152: 969-79.

[24] Ereskovsky AV. Reproduction cycles and strategies of coldwater sponges Halisarca dujardini (Demospongiae, Dendroceratida),
Myxilla incrustans and Iophon piceus (Demospongiae, Pocilosclerida) from the White Sea. Biol Bull 2000; 198: 77-87.

[25] Riesgo A, Maldonado M. Differences in reproductive timing among sponges sharing habitat and thermal regime. Invertebr Biol 2008; 127 (4): 357-67.

[26] Elvin DW. Seasonal growth and reproduction of an intertidal sponge, Haliclona permollis (Bowerbank). Biol Bull 1976; 151: 108-25

[27] Fell PE, Lewandrowski KB. Populaton dynamics of the estuarine sponge, Halichondria sp. within a New England eelgrass community. J Exp Mar Biol Ecol 1981; 55: 49-63.

[28] Pansini M, Pronzato R. Observation on the dynamics of a Mediterranean sponge community. In: Rützler K, Ed. New perspectives in sponges biology Smithsonian Institution Press, Washington DC 1990; pp. 404-15.

[29] Gaino E, Manconi R, Pronzato R. Organizational plasticity as a successful conservative tactis in sponges. Anim Biol 1995; 4: 3143.

[30] Bell JJ. Sponges as agents of biological disturbance. Mar Ecol-Prog Ser 2008; 368: 127-35

[31] Barthel D. Growth of the sponge Halichondria panicea in the North Sea habitat. In: Klekowski RZ, Styczynska-Jurewicz E, Falkowski L, Eds. Proceedings of the $21^{\text {st }}$ Eur Mar Biol Symp, Gdansk 1989; pp. 23-30.

[32] Bell JJ, Barnes DKA. Density, distribution and decline of two species of unattached demosponge. Sarsia 2002; 87: 110-8.

[33] Tanaka K. Growth dynamics and mortality of the intertidal encrusting sponge Halichondria okadai (Demospongiae, Halichondridae). Mar Biol 2002; 140: 383-9.

[34] Gaino E, Bavestrello G, Cerrano C, Sarà M. Survival of the calcareous sponge Clathrina cerebrum (Haeckel, 1872) on a vertical cliff during the summer crisis. Ital J Zool 1996; 63: 41-6.

[35] Maldonado M, Uriz MJ. Sexual propagation by sponge fragments. Nature 1999; 398: p. 476.

[36] Cecere E, Saracino OD, Fanelli M, Petrocelli A. Presence of a drifting algal bed in the Mar Piccolo basin, Taranto (Ionian Sea, Southern Italy). J Appl Phycol 1992; 4(3): 1-5.

[37] Calace N, Ciardullo S, Petronio BM, et al. Influence of chimica parameters (heavy metals, organic matter, sulphur and nitrose) on toxicity of sediments from the Mar Piccolo (Taranto, Ionian Sea, Italy). Microchem J 2005; 79: 243-8.

[38] De Serio F, Malcangio D, Mossa M. Circulation in a Southern Italy coastal basin: Modelling and field measurements. Continental Shelf Res 2007; 27: 779-97.

(C) Gaino et al.; Licensee Bentham Open.

This is an open access article licensed under the terms of the Creative Commons Attribution Non-Commercial License (http://creativecommons.org/licenses/by$\mathrm{nc} / 3.0 /$ ), which permits unrestricted, non-commercial use, distribution and reproduction in any medium, provided the work is properly cited 